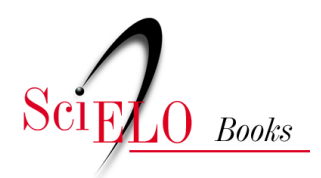

\title{
As redes geográficas, a escala e a economia as transformações no movimento da comercialização agrícola no Rio de Janeiro com base na centralidade das grandes varejistas
}

\author{
Rogério Seabra \\ Daniele Baú
}

\section{SciELO Books / SciELO Livros / SciELO Libros}

SEABRA, R., and BAÚ, D. As redes geográficas, a escala e a economia:

as transformações no movimento da comercialização agrícola no Rio de Janeiro com base na centralidade das grandes varejistas. In: MAIA, D. S., and MARAFON, G. J., eds. Ensino superior e desenvolvimento regional:

reconfigurando as relações entre as cidades e o campo [online]. Rio de Janeiro: EDUERJ, 2020, pp. 200-234. ISBN: 978-65-87949-08-6.

https://doi.org/10.7476/9786587949086.0008.

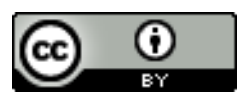

All the contents of this work, except where otherwise noted, is licensed under a Creative Commons Attribution 4.0 International license.

Todo o conteúdo deste trabalho, exceto quando houver ressalva, é publicado sob a licença Creative Commons Atribição 4.0.

Todo el contenido de esta obra, excepto donde se indique lo contrario, está bajo licencia de la licencia Creative Commons Reconocimento 4.0. 


\section{As REDES GEOGRÁFICAS, A ESCALA E A ECONOMIA: AS TRANSFORMAÇÕES NO MOVIMENTO DA COMERCIALIZAÇÃO AGRÍCOLA NO RIO DE JANEIRO COM BASE NA CENTRALIDADE DAS GRANDES VAREJISTAS}

Rogério Seabra Daniele Baú

\section{Introdução}

Becker (1966) relata um cenário bastante complexo e instável para a comercialização agrícola no Estado do Rio de Janeiro. O clássico O Mercado Carioca e seu Sistema de Abastecimento relaciona crescimento demográfico, produtividade e configuração do sistema de comercialização, apresentando as interações entre os diversos agentes envolvidos no processo.

A autora expressa a possibilidade geográfica (espacial) de estudar comercialização, produção e suas articulações e indica, em seguida, a potencialidade dos estudos geográficos na resolução de problemas de falta de abastecimento. Na publicação, o abastecimento é "um complexo sistema de relações que se estabelecem entre a produção, o armazenamento, o transporte, a comercialização e o consumo de alimentos" (1966, p. 33). 
Becker (1966) ainda ressalta a complexidade das interações que se originaram das possíveis perturbações do sistema, ou seja, uma alteração em um agente envolvido no processo exige um novo equilíbrio-forma para todo o sistema. Além disso, a autora exibe as conexões entre os canais de comercialização com outras estruturas da economia nacional, isto é, o sistema de abastecimento interage - em ação e reação - com a escala nacional na sua totalidade.

Desse modo, o texto conecta escalas geográficas e o sistema de abastecimento no Rio de Janeiro de 1966, incorporando os problemas e as necessidades oriundas do crescimento demográfico-metropolitano do antigo Estado da Guanabara e das áreas de produção. Isso posto, convém salientar a centralidade da demanda metropolitana e os entraves e conflitos com as estruturas produtivas e sociais nas áreas produtoras de gêneros agrícolas.

Portanto, Becker (1966) exibe em sua pesquisa a presença de novidades e permanências no sistema de abastecimento, com rebatimento direto na forma de produzir e na configuração dos canais de comercialização. Em outras palavras, relaciona-se campo e cidade pela perspectiva do abastecimento de gêneros agrícolas.

A demanda metropolitana é considerada a matriz para as alterações na produção e na organização dos canais de produção, já que o crescimento demográfico e de renda impóe um fluxo maior de produtos agrícolas, criando outros mecanismos de comercialização pautados em mais eficiência e velocidade. Destacando, ainda, permanências e novidades, Becker (1966) lembra que a demanda criada diversifica os canais de comercialização, indicando a constituição embrionária de nichos de mercado no consumo.

No texto mencionado, a Região Serrana aparece como uma importante área de produção de hortaliças destinadas ao mercado metropolitano. Os canais de comercialização estabelecidos eram articulados pelos atravessadores ou "intermediário especulador", responsável por levar a produção até o canal de venda direta para o consumidor. 
A presença histórica do atravessador no sistema de abastecimento carioca conduz à manutenção de particularidades no atual arranjo de comercialização. Na verdade, as principais transformações no canal de distribuição são derivadas das mudanças no perfil clássico do atravessador para os atuais operadores logísticos. Dotados de um arsenal técnico fantástico, as empresas de comercialização já articulam produção e redes varejistas entre a Região Serrana e a área metropolitana.

\section{Acumulação flexível e paradigma produtivo: a construção da flexibilidade como parâmetro competitivo}

A construção de um paradigma produtivo pressupõe um resultado derivado de diversos embates entre o novo e os velhos formatos de produção, além de, necessariamente, ser compreendido como um processo. A definição de um modelo produtivo hegemônico representará a liderança de uma forma sobre as outras, em convívio/conflito/ complementariedade e em constante transformação.

Dessa forma, as técnicas e as mudanças organizacionais, fundamentais para estabelecer padrões de eficiência para as empresas, derivam de critérios produtivos, relacionados ao conhecimento e às informações sobre os avanços tecnológicos e o jogo político previsto pelas relações sociais de produção. Assim, o padrão competitivo se faz dominante com origem na dinâmica sociopolítica, indicando a liderança de determinados segmentos sociais em uma determinada temporalidade. Portanto, as relações sociais, políticas, econômicas e produtivas (re)produzem o espaço geográfico de forma dialética, transformando esse processo em uma estruturação dinâmica, ou seja, em transformação.

Logo, a estruturação de um padrão competitivo e, consequentemente, produtivo-logístico, implica a adequação de modelos de gestão do trabalho, de comercialização e de espacialidade. Em geral, as referências para novos processos produtivos têm origem nos agen- 
tes mais fortalecidos e, por exercer a supremacia nas relações sociais de produção, estabelecem seus padrões como hegemônicos. No caso da comercialização agrícola, as grandes empresas varejistas desempenham esse papel central na dinâmica do abastecimento e, no mesmo contexto, da normatização das práticas, isto é, (re)criando normas e formas de comercialização, integrando ou marginalizando produtores ou empresas de menor porte.

As mudanças organizacionais e produtivas impactam para além das empresas, com rebatimento na (re)produção do espaço geográfico. A circulação do capital revela um processo extremamente dinâmico do ponto de vista técnico e espacial, influenciando a destruição criativa de sistemas produtivos, logísticos e ferramental tecnológico (Harvey, 2011 e Berman, 1999 e 2001).

As transformações técnicas, inseridas em contextos sociais e espaciais, constituem os pilares para a construção de novos paradigmas produtivos e logísticos em concordância com processos organizacionais de forma seletiva do ponto de vista socioespacial. Para Santos (2005), a compreensão da difusão das técnicas deve ser colocada a partir das ações temporais da sua propagação. Segundo o autor, os estudos sobre a transmissão das técnicas precisam evidenciar "que a história da difusão de inovações está sutilmente gravada no espaço” (p. 41).

Dessa forma, a (re)produção do espaço geográfico carrega sentidos passados e presentes, marcados pela racionalidade de reprodução ampliada do capital e pelos demais movimentos de resistência e consentimento assimetricamente associados aos múltiplos resultados da espacialidade. De forma pragmática, a racionalidade é traduzida, atualmente, por métodos com rótulos de eficiência, fluidez, flexibilidade e competitividade.

As transformações no processo produtivo-logístico são fragmentos do ímpeto "revolucionário" do capital, reconhecido por Harvey (2004) como destruição criativa. As mudanças e recriações nos arranjos socioespaciais repercutem em (re)criações de significados para o mercado, nas relações trabalhistas, nas diretrizes eco- 
nômicas etc. Nesse sentido, o capital produz normas e símbolos e os classifica como eficientes de acordo com as necessidades de sua própria expansão, apropriando-se (e ressemantizando) das relações espaciais e técnicas.

A ampliação ou a recuperação de elevadas taxas de lucro do investimento capitalista mobilizam obsolescência programada de produtos, normas e técnicas e, portanto, a construção de novos paradigmas produtivos e logísticos, novas técnicas, relações sociais de produção e arranjos espaciais. De acordo com os argumentos indicados por Harvey (2004),

As inovações alteram os mecanismos de produção, circulação e consumo, apresentando, do ponto de vista técnico, soluções para solucionar conjunturalmente os problemas gerados pelas próprias contradições inatas ao seu modelo de reprodução (p. 132).

O caráter dinâmico no desenvolvimento de técnicas propõe, atualmente, uma maior circulação de bens materiais e imateriais, acelerando o ciclo de reprodução do capital e criando parâmetros de eficiência para a movimentação dos fluxos. Por isso, o espaço recebe próteses (Santos, 2002) técnicas para tornar-se capaz de acelerar a troca de mercadorias e normas em escala global, em momentos e intensidades distintas em virtude dos embates entre processos hegemônicos e espacialidades historicamente pré-existentes.

As características técnicas, sociais, produtivas, espaciais e trabalhistas, estabelecidas por um determinado período, revelam as condições - um regime - de acumulação do capital por um determinado período, apontando para padrões hegemônicos sem, contudo, ter a capacidade de homogeneizar práticas e espaços.

De acordo com Harvey (2004),

A estabilização, por um longo período, da alocação do produto líquido entre consumo e acumulação; ele implica alguma corres- 
pondência entre a transformação tanto das condições de produção como das condições de assalariamento (p.117).

A estabilização dinâmica de normas exerce interações com as formas de concepção das relações sociais de produção e (re)produção do espaço geográfico. Nesse sentido, as relações entre distribuição e consumo de gêneros agrícolas são afetadas e, no caso do Estado do Rio de Janeiro, a centralidade dos supermercados na gestão dos fluxos marca o atual perfil da rede de comercialização agrícola.

Somando o que foi apresentado à contribuição de Chesnais e Sauviat (2005), aponta-se para as transformações na forma e intensidade das relações entre corporações. Por exemplo, no caso da produção industrial, as corporações articulam processos produtivos fragmentados buscando redução de custo, produtividade e qualidade. Assim, um automóvel é montado com peças providas por um fornecedor que pode estar localizado em outro país ou continente. Esse modelo orienta as práticas e as ações das principais empresas do planeta, pois representa um modelo de competitividade.

Em outra vertente, Boxberger e Klimenta (1999), ao apresentar o exemplo da Siemens, indicam a flexibilidade empresarial como uma estratégia estruturante das grandes corporações transnacionais. Para os autores,

Para produzir com um custo relativamente vantajoso, ela divide o processo de produção distribuindo-o por diversos países; produz onde é mais barato. As vantagens de custos de cada país, podem ser usadas de forma favorável através da construção de relações globais de fornecimento (p. 20).

A estratégia de produção fragmentada, flexível e globalizada é devidamente acompanhada pela otimização de processos logísticos para integração de cadeias mundiais de suprimentos. Diante desse quadro, as ferramentas logísticas são colocadas no mesmo patamar 
dos instrumentos produtivos, constituindo verdadeiros diferenciais competitivos, principalmente para as grandes empresas transnacionais.

Portanto, a conformidade de um paradigma produtivo-logístico relaciona uma significativa variedade de processos sociais, econômicos, políticos, espaciais e corporativos. Em interação, os padrões são soerguidos ao patamar de hegemonia, passando a direcionar práticas cotidianas de empresas, trabalhadores, poder público, produtores agrícolas etc.

A configuração espacial é influenciada pelas transformações contextualizadas pelas alterações no paradigma competitivo como um processo em constante transformação. As mudanças espaciais atreladas aos anseios da acumulação têm vínculo direto com processos de integração e marginalização de determinadas áreas e com conflitos entre novas e velhas formas. $\mathrm{O}$ atual se sobrepõe, apropria e estimula o passado de acordo com as necessidades da acumulação ou com base nas relações de poder estabelecidas pelas forças produtivas em uma determinada área ou temporalidade. Logo, de acordo com Santos (2002), para analisar as dinâmicas espaciais de hoje, é fundamental compreender os processos históricos constituidores e articuladores dessas práticas.

Seguindo a premissa anteriormente apresentada e com os argumentos de Ferreira (1997), Harvey (2004 e 2005) e Palmeira e Tenório (2002), compreende-se a atual hegemonia da fluidez e da flexibilidade como decorrência não linear do paradigma produtivo pautado na rigidez. Na verdade, como já enunciado, há convívio de formas ou, em outras palavras, vivências parciais desses processos, seja pela resistência ao novo, seja imposição do novo, seja pela inserção marginal nas dinâmicas de reprodução ampliada do capital.

A construção de paradigmas produtivos passa por processos materiais e imateriais, técnicas e regras estabelecidas por relações assimétricas de poder. No caso da comercialização agrícola, a presença física das grandes redes varejistas, centralizando a gestão dos 
fluxos, não elimina outros modos de distribuição de gêneros agrícolas. Na verdade, amplia as formas de inserção de produtores e operadores logísticos em determinados períodos, flexibilizando (ou não) o acesso de agricultores familiares e empresas de distribuição de acordo com a demanda do mercado consumidor da área metropolitana, ou baseada na eficiência e produtividade de cada agente na rede de comercialização.

Concordando com Santos (2002), entende-se a relação entre a elaboração de paradigmas produtivos como uma íntima articulação de elementos sociais, espaciais e técnicos, (re)orientadores dos arranjos produtivos e das espacialidades, garantindo a constante dinâmica de ascensão e fragilização de próteses espaciais e normas, ou seja, uma imbricada interação entre um sistema de objetos e um sistema de ações em equilíbrio dinâmico.

Nesse contexto, as ferramentas logísticas transportam fundamentos socioeconômicos definidores da racionalidade considerada necessária para a reprodução do capital em uma determinada temporalidade. Os parâmetros de eficiência exigidos atingem campo e cidade com novas ações e instalação de novos objetos promotores de interações espaciais mais intensas e com pontos próximos e distantes.

As técnicas são mercadorias, e a sua difusão seletiva rebate na divisão do trabalho para as forças produtivas e no arranjo espacial. São, portanto, processos que, englobando as empresas, superam o ambiente corporativo e influenciam na sociedade e, obviamente, nos Estados. De acordo com Carlos (2011),

Mas o processo de produção de mercadorias se realiza produzindo não só a divisão técnica do trabalho dentro da empresa, a divisão entre processo de produção e processo de circulação, mas, também, produzindo relações sociais mais amplas e complexas que extrapolam as esferas da empresa e tomam a sociedade como um todo (p.49). 
Desse modo, o rebatimento atua, também, no poder estatal, em geral, por meio de políticas públicas de financiamento, assistência técnica, compra de produtos agrícolas, organização da comercialização etc. Da mesma forma que a construção social, espacial e técnica está envolvida na formulação de paradigmas produtivos e logísticos, as análises sobre o papel do Estado são estabelecidas com base na compreensão não linear de um processo histórico.

Simplificando os argumentos de Lastres e Ferraz (1999), Antunes (2001), Lipietz (1991) e Ferreira (1997), verificam-se mudanças representativas no papel do Estado na análise das mudanças nos paradigmas produtivos, ou seja, da necessidade de reconhecer o poder público como regulador das relações sociais de produção e do papel atual de indutor das práticas mercadológicas.

No Brasil, o poder público atuou na comercialização a partir da criação de mercados atacadistas. As centrais foram pensadas para articular produção e consumo com o objetivo de unificar a produção agrícola e, por isso, servir como grande entreposto comercial regulando oferta, demanda e preço. No Brasil, essa conjuntura permitirá a criação das centrais de abastecimento, entre elas, o sistema CEASA-RJ.

Segundo Harvey (2004), as principais condições para a transformação no paradigma produtivo-logístico passam na regulação e intervenção estatal nos mecanismos de reprodução ampliada do capital. Já Lipietz (1991) e Ferreira (1997) lembram que a mediação estatal reduziu a taxa líquida de lucro, sendo, consequentemente, o estopim para a crise.

Harvey (2003) indica uma conjuntura capaz de reforçar a transição da regulação estatal para a regulação mercadológica. Para o autor,

A profunda recessão de 1973, exacerbada pelo choque do petróleo, evidentemente retirou o mundo capitalista do sufocante temor da estagflação (estagnação da produção de bens e alta inflação de preços) e pôs em movimento um conjunto de processos que solaparam o compromisso fordista (p. 140). 
Outra contribuição para essa argumentação vem de Smith (1988). O autor separa crise-recessão capitalista de contradição; ou seja, os momentos de crise são fundamentais para (re)organizar as forças produtivas, os arranjos espaciais, as relações trabalhistas e a ampliação das taxas de lucro. Segundo Smith (1988),

As fusões, encampações e falências, assim como a desvalorização geral (das mercadorias, da força de trabalho, da maquinaria, do dinheiro) e a destruiçãa do capital (tanto variável quanto do constante), que acompanham a as crises, também preparam o terreno para nova fase de desenvolvimento capitalista (p. 185).

Finalmente, Soares (2010) relaciona a crise do modelo regulador keynesiano com os entraves gerados pela própria contradição inata ao movimento de reprodução do capital. Como afirma o autor,

Prosperidade e, por sintonia desenvolvimento são medidos, segundo o discurso keynesiano, pela renda que os indivíduos detêm: rendas individuais altas constituem indicativo de que a economia está bem, e queda de renda sinaliza que ela está mal. Assim, o dinamismo, a vitalidade econômica, fundamenta-se no fluxo de renda, na transferência de dinheiro de mão para mão. $\mathrm{O}$ problema reside, portanto, na interrupção desse fluxo, porque, nesse caso, à sociedade estaria sendo devolvido menos do ela fornece aos indivíduos (p. 66).

Nesse sentido, a transição no paradigma produtivo e o estabelecimento de novas metas e padrões de competitividade foram construídos pela busca de flexibilidade nos processos de produção, viabilizada por novas técnicas e ferramentas de gestão organizacionais. De fato, tais alterações são dialeticamente relacionadas à (re) produção do espaço geográfico e, assim sendo, a fluidez e o padrão reticular serão transformados em parâmetros fundamentais para a reprodução do capital compreendido como modelo societário. 
Como já apontado, convém ressaltar a manutenção de formas e de processos de temporalidades distantes. Logo, a transição e as mudanças na (re)produção do espaço não indicam a eliminação de posturas e perfis de outrora, apenas o indício de uma transição de indicadores de competividade do capital.

O paradigma produtivo-logístico no ambiente corporativo transforma a inovação tecnológica em um imperativo, impulsionando de forma contínua os ganhos de produtividade oriundos da introdução de novas máquinas e novos equipamentos na produção e na logística. A flexibilização também (re)cria novos padrões de localização do processo produtivo, tornando-o fragmentado e mutável de acordo com as transformações na demanda de consumo.

A volatilidade inserida no discurso da flexibilização dos processos produtivos e técnicos também faz-se presente no conflito entre as forças produtivas e o capital. No caso da comercialização agrícola, verifica-se a inserção sazonal/múltipla dos produtores como uma faceta da flexibilização; entretanto, também é preciso compreender a inserção/marginalização efêmera dos produtores como mecanismo de resistência dos produtores familiares na área serrana fluminense.

Outro advento impulsionado pela flexibilidade dos processos é a subcontratação/terceirização. Nesse aspecto, é fundamental destacar a posição do produtor como um fornecedor terceirizado de produtos agrícolas, ou seja, um prestador de serviços para o varejista, da mesma forma que o operador logístico representa um processo de terceirização para algumas redes varejistas localizadas na área metropolitana do Estado do Rio de Janeiro.

Em virtude de tais princípios, a inovação tecnológica ganha um caráter peremptório e, simultaneamente e intencionalmente, distancia-se do sentido político e social inerente à sua construção. Logo, o insofismável desenvolvimento tecnológico surge como elemento autônomo, reduzindo os entraves econômicos, sociais e políticos ao simples desenvolvimento de novas técnicas. O paradigma produtivo-logístico flexível inova de forma constante e difunde as 
técnicas de forma desigual, ampliando assimetrias de poder (re) criando mecanismos de diferenciação socioespaciais.

A técnica, quando erroneamente considerada apolítica, ganha um papel de mediadora nas relações sociais e econômicas entre produtores, operadores logísticos e redes varejistas. Afinal, nesse meio, a técnica ganha centralidade como agregadora de valor, seja no processo produtivo, seja na eficiência logística, garantindo acesso mais qualificado aos diferentes segmentos do mercado consumidor. Seguindo tais preceitos, Silveira (2005) afirma que

Neste novo regime de acumulação, passa-se a priorizar a inovação tecnológica e a reestruturação e flexibilização do processo de produção, a valorizar a gestão e a economia de escopo afinadas com a dinâmica do mercado consumidor e a aprofundar o processo de circulação de capital, de informação e de mercadorias (p. 221).

A flexibilidade evidencia o papel das técnicas sob nítida relação com o discurso de fluidez, aceleração, livre circulação, terceirização, inovação, fragmentação, eficiência, produtividade e desregulamentação. A capacidade de adaptação, de atendimento aos novos (e criados) anseios do mercado consumidor e a de (re)criação de oportunidades de investimentos está conectada (como sempre) à reprodução ampliada do capital ao processo de (re)produção do espaço geográfico.

O inconstante e o efêmero são conduzidos ao lugar da naturalização com base na criação de falsos consensos moldados de relações assimétricas de poder (Moreira, 2007). Nesse sentido, Harvey (2003) articula flexibilidade e neoliberalismo transformados em dogmas mercadológicos, soerguidos ao patamar de hegemonia e de modelo de padrões de competitividade. 


\section{A orientação econômica da flexibilidade: o neoliberalismo como oportunidade de investimentos transnacionais}

A transformação da base técnica é de extrema importância na configuração de novos processos organizacionais e logísticos, que, em interação, produzem o arcabouço fundante de parâmetros competitivos de um paradigma produtivo. A enorme diferença técnica entre os atores envolvidos nas cadeias de suprimentos garante a maior capacidade de gestão dos fluxos para determinados atores fazendo-os hegemônicos.

Partindo do exposto anteriormente, fica nítida a permanência de processos pretéritos diante de novos padróes, uma vez que o novo se faz hegemônico de acordo com o estabelecido social e historicamente. Nesse sentido, aponta-se para o convívio não harmônico, porém entrelaçado. Santos (2000) explica a relação entre atores de temporalidades distintas:

Ao surgir uma nova família de técnicas, as outras não desaparecem. Continuam existindo, mas o novo conjunto de instrumentos passa a ser usado pelos novos atores hegemônicos, enquanto os não hegemônicos continuam utilizando conjuntos menos atuais e menos poderosos (p. 25).

Logo,

Quando um determinado ator não tem condições para mobilizar as técnicas consideradas mais avançadas, torna-se, por isso mesmo, um ator de menor importância no período atual (p. 25).

Estruturando os argumentos, observa-se uma transformação técnica em sintonia com os processos socioespaciais, ambos de caráter dinâmico, ou seja, em transformação constante. Da mesma forma, o arranjo espacial torna-se um resultado em processo, sempre 
conjuntural e permeado pelo movimento de redes geográficas. Os processos de integração/marginalização são normatizados e normalizados por padrões técnicos e por um discurso político-econômico de sustentação da reprodução ampliada e acelerada do capital.

$\mathrm{O}$ modelo neoliberal respondeu aos entraves gerados no momento anterior. Como aponta Anderson (1995), apesar de originário do momento pós-guerra, precisamente em 1944, com o lançamento do livro "O Caminho da Servidão", de Friedrich Hayek, em contraponto ao nascente estado de bem-estar social, a ascensão do neoliberalismo ocorreu num momento de crise do modelo keynesiano (de intervenção estatal), nas décadas de 1970 e 1980. A crise do modelo econômico iniciado após a II Guerra Mundial gerou uma profunda recessão e a elevação das taxas inflacionárias, garantindo o espaço para a expansão do ideário neoliberal. O diagnóstico para a crise do sistema keynesiano foi o excesso de poder dos trabalhadores, que resultou em melhores salários, e os gastos relacionados aos mecanismos de intervenção do poder público em detrimento da ampliação da taxa de lucro.

Feito o diagnóstico, a solução proposta atacou a origem da crise, ou seja, a ruptura com os sindicatos e os cortes dos gastos públicos considerados ineficientes para a promoção do crescimento econômico. Essa receita, implementada no Brasil, principalmente após a ditadura civil-militar, será importante para (re)considerar a atuação do Estado na configuração de mercados atacadistas para a distribuição de gêneros agrícolas no Estado do Rio de Janeiro.

Dessa forma, a estruturação do neoliberalismo dogmático estabeleceu uma redução da esfera política para o debate racional-técnico equivocadamente considerado apolítico. Segundo Harvey (2012),

Nenhum modo de pensamento se torna dominante sem propor um aparato conceitual que mobilize nossas sensações e nossos instintos, nossos valores e nossos desejos, assim como as possibilidades inerentes ao mundo social que habitamos. Se bem-sucedido, 
esse aparato conceitual se incorpora a tal ponto ao senso comum que passa a ser tido por certo e livre de questionamento (p. 15).

Em associação, Anderson (1995) aponta que

Política e ideologicamente, todavia, o neoliberalismo alcançou êxito num grau com o qual seus fundadores provavelmente jamais sonharam, disseminando a simples ideia de que não há alternativas para os seus princípios, que todos, seja confessando ou negando, têm de adaptar-se a suas normas (p. 23).

De acordo com Harvey (2012), a ação estatal muda de papel e sai da regulamentação/intervenção para a indução da liberdade do mercado. Diante desses preceitos e com o desenvolvimento de novas técnicas de comunicação e transporte, a escala de ação das empresas torna-se global, a circulação de capital é instantânea e mundializada e o estado de caráter keynesiano é duramente reduzido.

Ainda seguindo Harvey (2012), praticamente livre das regulações públicas, o mercado global, longe de ser uma invenção neoliberal, é potencializado pela enorme variedade de oportunidades de vantagens comparativas elencadas via diferenciação espacial. As normas, as técnicas e o capital fluem em escala global, buscando a territorialização, mesmo que efêmera, em áreas com elevado potencial de retorno para os investimentos. Nessa linha, o autor aponta que "os vínculos internacionais sempre foram importantes, contudo, não há dúvidas que houve uma ampliação” (p. 44).

Fluidez, redes, fluxos e flexibilidade formam um inextricável conjunto de símbolos e representações de agentes hegemônicos e do receituário neoliberal. Assim, seguindo os argumentos de Soja (1993), compreende-se o capital como um modelo societário e sociedade e espaço como "componentes dialéticos" (p. 99). Logo, o espaço deve ser encarado como um produto em transformação do movimento social ou, nas palavras do autor, espacialidade. 
Presente e entrelaçado ao cotidiano, o neoliberalismo

se tornou hegemônico como modalidade de discurso e passou a afetar tão amplamente os modos de pensamento que se incorporou às maneiras cotidianas de muitas pessoas interpretarem, viverem e compreenderem o mundo (Harvey, 2012, p. 13).

Na conjuntura neoliberal, a (re)produção do espaço viabiliza a circulação de capitais e a montagem de investimentos estrangeiros diretos, ou seja, uma nomenclatura específica para, por exemplo, compras e fusões de uma empresa pelo capital estrangeiro, resultando em ampliação de processos de oligopolização em diversos segmentos do mercado.

Esse contexto é fundamental para compreender uma significativa alteração na rede de comercialização entre a Região Serrana fluminense e a Região Metropolitana. Em especial a partir da década de 1990, a abertura da economia brasileira viabilizou a entrada de capitais transnacionais e, dentre eles, a entrada de redes varejistas internacionais, acelerando as transformações no padrão produtivo-logístico e, principalmente, alterando a escala competitiva.

É justamente a partir desse momento e por essa concepção que a soberania dos Estados é moldada para sustentar a livre circulação de capitais e mercadorias - ensejada pelas inovações técnicas -, estimulando os processos de concorrência e competividade (na teoria) em escala global e criando oportunidades para a entrada dos IED (Investimentos Estrangeiros Diretos) - Segundo Harvey (2012),

A soberania do Estado com relação aos movimentos de mercadoria e de capital é entregue de bom grado ao mercado global. A competição internacional é tida como algo saudável, já que melhora a eficiência e a produtividade, reduz os preços e, dessa maneira, controla as tendências inflacionárias (p. 76). 
A relação construída entre o arcabouço neoliberal e os Estados é orientada pelo empenho estatal em buscar a redução de barreiras físicas e legais para o avanço da integração do mercado nacional com o globalizado, mesmo que isso represente a redução da participação de empresas nacionais - públicas ou privadas - em seu mercado interno. Nesse sentido, diante do processo de globalização neoliberal, a concorrência entre grandes varejistas transnacionais reduz o número de competidores tendenciosos ao oligopólio e ao fortalecimento de poucas e gigantes empresas.

A concorrência e a competitividade determinam pressupostos técnicos e normas, tendendo à dilatação da desigualdade entre os agentes envolvidos na comercialização, já que a concorrência deriva do acesso uniforme às técnicas e às informações por parte dos agentes do mercado. Como isso não ocorre, há expansão na desigualdade de gerenciar os fluxos circulantes na rede de comercialização. Portanto, concorda-se com a seguinte afirmação de Harvey (2012),

Por conseguinte, as relações assimétricas de poder tendem antes a aumentar do que diminuir com o passar do tempo, a não ser que o estado aja para se contrapor a elas. $\mathrm{O}$ pressuposto neoliberal de perfeito acesso a informações e de igualdade de condições na competição parece ser ou inocente ou um escamoteamento deliberado de processos que vão levar à concentração de riqueza e, portanto à restauração do poder de classe (p. 79).

O resultante desses processos aparece, por exemplo, na obra de Berg e Roberts (2012) sobre a vitoriosa expansão da rede Walmart no cenário internacional até tornar-se um dos maiores varejistas do planeta. Para os autores, o crescimento e a centralidade da empresa reflete sua capacidade de influenciar fornecedores e eliminar atravessadores ao longo da cadeia de suprimentos. Nas palavras dos autores, 
Não apenas a empresa tornou-se a maior cadeia varejista no mundo, com uma liderança que é improvável de ser desafiada por qualquer outra cadeia varejista, exceto a Amazon, mas também sua influência sobre as cadeias varejistas globais mais amplas e indústrias de bens de consumo tem sido praticamente imensurável (Berg e Roberts, 2012, p. 1).

A citação anterior é importante para retomar os argumentos técnicos e políticos sobre a construção de paradigmas competitivos, ou seja, a capacidade do Walmart de gerenciar e orientar os fluxos determina uma centralidade intensa, capaz de impor racionalidades externas para os fornecedores. O detalhe, para esse caso, é a influência da rede varejista sobre empresas gigantescas, como a Procter \& Gamble. A assimetria de poder fica sem precedentes quando se compara o poder das grandes redes com outros agentes de comercialização, como produtores familiares e operadores logísticos.

Na verdade, os supermercados são importantes para analisar o período de transição ao paradigma flexível, ou seja, as grandes redes de autoabastecimento ascenderam durante o período de regulação estatal, com maior controle das fronteiras econômicas e, consequentemente, relativa garantia de mercados nacionais e ampliação de mercados consumidores.

O Walmart, em particular, foi empurrado pelo consumismo no seu país natal, pela amplificação do trabalho feminino (demanda por produtos "práticos") e pela ampliação de linhas de crédito (para consumidores e empreendedores). Entretanto, em pouco tempo, a rede, buscando uma manutenção de redução de preços ao consumidor, produziu intensa transformação na relação com os seus fornecedores, flexibilizando a origem dos produtos, (re)criando sistemas técnicos e logísticos, adequando a produção, as entregas e o consumo para reduzir as unidades de manutenção de estoque e elevando a produtividade da mão de obra nas filiais. 
Para Berg e Roberts (2012) "o Walmart acabou com os intermediários, eliminou redundâncias, reduziu o custo de embalagens, investiu em tecnologia, consolidou compras e pressionou fornecedores, tudo em nome da oferta de produtos a um preço baixo" (p. 15). O empenho em reduzir preço ao consumidor tem impacto ao longo de toda a cadeia de suprimentos, determinando normas e técnicas para ser inserido na rede de fornecedores do Walmart e implicando uma hegemonia no controle dos fluxos e das normas. Nas palavras dos autores,

À medida que o Walmart cresceu e tornou-se mais poderoso, ele foi capaz de alcançar melhores condições com os fornecedores. Sua escala significa que os custos mais baixos de compra poderiam ser reinvestidos em preços mais baixos na prateleira (p. 59).

Esse jogo, quando estabelecido em escala global se aproxima dos argumentos de Boxberger e Klimenta (1999) em relação à negociação entre empresas e fornecedores. Em outras palavras, a fragmentação do processo produtivo da Siemens ou a busca por preço baixo para o consumidor do Walmart revela a prática do "global sourcing" das grandes cadeias transnacionais. $\mathrm{O}$ fornecedor de um produto ou serviço pode estar em qualquer parte do mundo desde que siga normas básicas de qualidade e eficiência na entrega.

Esse dado explica, na prática, a movimentação das redes varejistas e o processo de inclusão e marginalização dos fornecedores. Contudo, vale destacar que essa prática encontra, no caso da comercialização agrícola na Região Serrana do Estado do Rio de Janeiro, produtores familiares buscando práticas alternativas/autônomas de integração com os consumidores da área metropolitana.

O neoliberalismo sustentará politicamente as articulações transescalares das grandes empresas com a livre circulação de fluxos financeiros e estruturação dos IEDs - garantindo a internacionalização de grandes grupos varejistas por meio da livre circulação de 
mercadorias e serviços -, permitindo, via global sourcing, a inclusão/ marginalização dinâmica de fornecedores em praticamente qualquer lugar do planeta.

A regulação estatal perde espaço para as diretrizes do mercado, criando novos sentidos para o papel do Estado e limites entre o público e o privado. Nesse caso, como indicado anteriormente, o papel outrora desempenhado pelos mercados atacadistas criados pelo Governo Federal brasileiro serão duramente alterados, da mesma forma que haverá mudanças nas técnicas e nos operadores logísticos atuantes no Estado do Rio de Janeiro e nos (re)produtores da rede de comercialização de produtos agrícolas.

A inclusão/marginalização de produtores e operadores logísticos depende do comportamento e das necessidades do mercado consumidor; na verdade, dos mecanismos de criação de demandas geradas da mercantilização de necessidades e do estabelecimento de processos contínuos de abastecimento. Novamente, no caso do Walmart, durante o fortalecimento e crescimento da rede nos EUA, a demanda estava garantida pelo aumento da massa salarial em virtude dos ganhos reais de salários. Entretanto, diante da flexibilização dos processos produtivos e logísticos, a rede passa por adequações, principalmente em sua ação internacional, para ajustar suas práticas aos diferentes nichos de mercado estabelecidos no momento atual. A configuração de mercados específicos é uma estratégia de vendas importante para a produção de novas demandas e, como estratégia logística, utiliza todo o potencial técnico para organizar estoques e regular as relações entre varejistas e fornecedores.

Aliás, a configuração de uma rede de comercialização passa, necessariamente, por constantes transformações justamente para buscar outros consumidores. Para atuar dessa forma, serão necessários variados produtores, outros operadores logísticos e novas técnicas para a distribuição dos produtos agrícolas sob o paradigma flexível - just in time. 
Tratando desse assunto, Harvey (2011), ao examinar o comportamento da reprodução do capital, trabalha, em primeiro lugar, com a possibilidade da expansão espacial do capital, ou seja, a inclusão de novos territórios no processo de reprodução ampliada e, em seguida, com a necessidade de (re)criação de formas de ampliar as taxas de lucro. A construção de novos paradigmas produtivo-logísticos e a necessidade de compreender o campo para além do agrícola representam esses mecanismos de reprodução/recreação das ferramentas de ampliação do capital, pela constante busca por oportunidades de reinvestimentos, com rebatimentos diretos nas práticas locais cotidianas dos produtores familiares da Região Serrana do Estado do Rio de Janeiro.

Encontrar ou construir áreas para alocar reinvestimento está articulado com a dinâmica dos fluxos e busca por fluidez no período contemporâneo. Assim, as práticas neoliberais, entre elas a constante inovação técnica e logística, entendidas pela conjuntura de ampliação da circulação do capital, constroem o cenário de expansão das grandes redes varejistas e a sua atuação no Rio de Janeiro, alterando as condições de comercialização e a produção de gêneros agrícolas. Para Harvey (2011),

Atritos ou barreiras a esse movimento espacial tomam tempo para ser negociados e diminuem a circulação. Ao longo da história do capitalismo muito esforço tem sido posto, portanto, na redução do atrito de distância e dos obstáculos à circulação. Inovações nos transportes e comunicações têm sido cruciais. Aumentar a abertura das fronteiras do Estado ao comércio e finanças, assinar acordos de livre-comércio e garantir um bom enquadramento jurídico para o comércio internacional também são vistos como essenciais a longo prazo (p. 43).

Os mecanismos econômicos, técnicos, políticos e simbólicos necessários ao capital para garantir a sua reprodução ampliada são fundamentais para, periodicamente, transformar as condições 
espaciais (Harvey, 2011). As destruições e crises são essenciais para a reconstrução de outras espacialidades, sobrepondo-se, sem eliminar a antiga, indicando a presença de embates e somatórias de temporalidades em convívio conflituoso e harmonioso ao mesmo tempo.

Também é importante analisarmos o tipo de intervenção estatal ao longo da consolidação da acumulação flexível como paradigma hegemônico. Para Delgado (2008), a produção agropecuária foi alvo da intervenção pública pelo reconhecimento de "falhas no funcionamento dos mercados" (p. 18), dificultando a comercialização e, consequentemente, o abastecimento alimentar.

A atuação de grandes redes varejistas no Brasil, sobretudo a partir de fusões e aquisições de empresas nacionais, alterou também as bases do processo de comercialização de gêneros agrícolas inclusive para varejistas nacionais. Diferente da abordagem de Berg e Roberts (2012), pautada em benefícios para as redes nacionais, as empresas brasileiras, na verdade, sobreviventes da competição com o capital transnacional, seguiram o padrão competitivo de normas e técnicas e, por isso, continuam atuando no abastecimento de gêneros agrícolas.

Pensando na espacialidade resultante, compreende-se a conservação de redes nacionais pela permanência de processos anteriores e pelo caráter particular de local, ou seja, a ação verticalizada não impõe uma universalização de formas práticas e formas espaciais. Há, então, um embate de formas na constituição da rede de distribuição de gêneros agrícolas que resulta de ações externas combinadas com o processo horizontal histórico-espacial.

O paradigma produtivo-logístico associado à globalização neoliberal produz a mercantilização de funções outrora públicas. Quando há possibilidade de apropriação de alguma forma de renda ou de reprodução do próprio capital, além de, como aponta Woods (2011), uma nova regulamentação para as práticas de produção e comercialização agrícola, o "neoliberalism has led in pratice not to the deregulation of agriculture, but to the re-regulation of agricul- 
ture with market-oriented rationality" ${ }^{1}$ (p. 250). Nesse sentido, buscando mais eficiência, a racionalidade neoliberal indica práticas de terceirização das atividades menos centrais para as empresas, que, no caso da comercialização agrícola no Estado do Rio de Janeiro, apontam para uma nova qualificação dos atravessadores, agora operadores logísticos; isto é, empresas de transporte que levam os produtos da área de produção até os locais de consumo.

Ainda de acordo com Woods (2011), o arsenal técnico e normativo do neoliberalismo estrutura a concorrência entre os produtores e, em seguida, com a entrada das multinacionais, os agricultores adequados aos parâmetros de preço, prazo, qualidade, técnica e relações trabalhistas acessam o mercado consumidor final com a intermediação dos grandes varejistas. Os padrões construídos são estabelecidos pela capacidade transescalar das grandes redes varejistas, independente do destino final da produção, como é o caso das olerícolas e hortícolas produzidas no circuito Tere-Fri.

De forma simplificada, há um novo arranjo de forças e territorialidades em disputa na mutável estruturação da rede de comercialização agrícola no Estado do Rio de Janeiro. Novos agentes e técnicas horizontalmente constituídos são (re)produzidos a partir do contato de racionalidades externas - transescalares - simbolizadas, essencialmente, pelas grandes redes varejistas em atuação na área metropolitana e, consequentemente, no Brasil e no mundo.

\section{A distribuição de gêneros agrícolas no Estado do Rio de Janeiro e as escalas de interação: os agentes em jogo e o jogo entre os agentes}

A administração de cadeias de suprimentos é um diferencial logístico e competitivo para as grandes corporações, que viabilizam, ou não, a expansão de determinados grupos empresariais nos maio-

${ }^{1}$ Neoliberalismo levou à prática, não à desregulamentação da agricultura, mas a re-regulação da agricultura com racionalidade orientada para o mercado (Tradução nossa). 
res e principais mercados consumidores do planeta. Dessa forma, a logística é compreendida como um processo empresarial muito maior do que o transporte de cargas e ganha destaque na configuração espacial das empresas no atual período econômico.

De fato, pensando na comercialização das hortícolas e olerícolas produzidas no circuito Tere-Fri e no modelo de terceirização, ou seja, na contratação de operadores logísticos terceirizados pelas grandes redes varejistas, em outra escala de análise, (re)configura-se a rede de abastecimento de gêneros agrícolas no Estado, inserindo, pelas normas e padróes de competividade, a escala local com a escala global e o caráter transescalar da atuação dos supermercados.

Os estabelecimentos agrícolas dos municípios de Teresópolis e Nova Friburgo destinam a maior parte da produção para a comercialização como podemos visualizar na tabela 17. Portanto, a logística é um diferencial fundamental para viabilizar o escoamento e a viabilidade dos negócios - a configuração e o controle da rede de distribuição é fundamental para os principais operadores logísticos da Região Serrana e das grandes redes de supermercado.

Tabela 17 - Quantidade produzida na horticultura - quantidade vendida de produtos da horticultura, Ano - 2017

\begin{tabular}{lcc}
\hline & \multicolumn{2}{c}{ Produtos da horticultura - Total } \\
\hline Município & $\begin{array}{c}\text { Quantidade produz- } \\
\text { ida na horticultura } \\
\text { (Ton) }\end{array}$ & $\begin{array}{c}\text { Quantidade vendida de produtos da } \\
\text { horticultura (Ton) }\end{array}$ \\
\hline Nova Friburgo (RJ) & 91175 & 90102 \\
\hline Teresópolis $(\mathrm{RJ})$ & 112836 & 101352 \\
\hline
\end{tabular}

Fonte: IBGE - Censo Agropecuário

A escala trabalhada é, conforme Castro (2001), um recurso para "aproximação do real" (p. 118) e para a compreensão das interações entre diferentes níveis de análise do fenômeno da comercialização. Portanto, encontra-se distante das referências matemáticas e 
geométricas da escala cartográfica e há a preocupação com as interações entre os diferentes planos de análise e a percepção/pertinência do fenômeno.

Segundo Castro (2001),

A escala é, na realidade, a medida que confere visibilidade ao fenômeno. Ela não define, portanto, o nível de análise, nem pode ser confundida com ele, estas são noções independentes conceitual e empiricamente. Em síntese, a escala só é um problema epistemológico quando definidora de espaços de pertinência da medida dos fenômenos, porque enquanto medida de proporção ela é um problema matemático (p. 123).

De acordo com a citação e a contribuição de Rua (2007), as análises mediadas pelo conceito de escala geográfica permitem verificar como "as desigualdades inerentes ao capitalismo impõem vivências desiguais da escalaridade" (p. 273). No caso da comercialização agrícola, pressupõe-se que as interações entre diferentes agentes operando na rede de abastecimento são operadas por diferentes graus de centralidade e capacidade de gestão de fluxos. Nesse sentido, a vantagem de operar de forma transescalar rebate na centralidade dos agentes em construir, a partir das relações assimétricas de poder, as normas de competividade feitas hegemônicas por um falso consenso social.

A escala, nessa leitura e conforme as contribuições de Castro (2001), representa uma perspectiva analítica do movimento de (re) produção do espaço geográfico. Logo, os embates e os interesses dos diferentes grupos sociais estarão em jogo horizontal e vertical, simultâneo e integrado.

Nesse sentido, de acordo com Brandão (2003), compreendem-se os entraves e as limitações da escala local no campo como forças da espacialidade global e verticalizada. $\mathrm{Na}$ verdade, não há formas de isolamento, ou seja, há interações dialéticas entre socie- 
dade e espaço-escala fundamentadas na articulação e na força desigual entre os agentes. Por isso, o local está inserido em processos transescalares e, necessariamente, movimenta-se a partir de inequidades geradas pela reprodução ampliada do capital. Segundo Brandão (2003), para o local, as normas, os padrões de competitividade e a inserção em redes globais são leituras exógenas de características produzidas internamente.

A inserção do local em redes mais amplas é fruto de uma construção social interativa - em outras palavras, depende do jogo assimétrico de forças impositivas, de movimentos de resistência, das adequações dos consentimentos e das cooptações. Portanto, pensando na comercialização agrícola no Estado do Rio de Janeiro, os entraves e as perspectivas para os produtores familiares da Região Serrana não passam exclusivamente por formas de colaboração/solidariedade/cooperação entre eles na escala local, mas, na verdade, pela capacidade (ou incapacidade) de centralizar fluxos de forma transescalar da mesma forma que os agentes hegemônicos.

Tal referência vem dos argumentos apresentados por Brandão (2003). Segundo o autor,

O certo é que a capacidade de ter centros de controle e de decisão internos à localidade, tendo por base a própria dinâmica endógena é bastante questionável. Qualquer embate com estas visões ingênuas e voluntaristas deve partir das determinações mais profundas de um regime social de produção - capitalismo - que necessariamente leva às últimas consequências a mercantilização e o aprofundamento recorrente da divisão social do trabalho em todas as possíveis dimensões temporais e escalas espaciais (p. 4).

A ênfase apenas no local contribui para a diferenciação espacial e, consequentemente, para a construção de vantagens comparativas de investimentos (Harvey, 2005 e 2011). Em contrapartida, a análise globalista tende a homogeneizar processos e espacialidades 
por não reconhecer o processo histórico e temporalidades horizontais interativas ao global. Por isso, além de reforçar a proposta analítica pautada em interações transescalares, as análises localistas e globalistas corroboram o receituário neoliberal de enfraquecimento da escala nacional na mediação da construção dos atuais padrões de competitividade.

Os pequenos produtores familiares no circuito Tere-Fri organizados, em geral, em sistemas de parceria, têm parte de sua renda absorvida ao longo do processo produtivo e de comercialização. Os parâmetros técnico-logísticos de eficiência e produtividade não alteraram o padrão assimétrico de poder entre os agentes. Ampliaram, sim, em sintonia com o movimento da reprodução do capital de (re)produzir hierarquias escalares.

Na verdade, Vieira (2012), Fernández (2009) e Smith (2004) abordam a escala nacional de forma bastante distinta. O primeiro reforça a possibilidade de mediação do Estado, praticamente um retorno ao modelo regulador de caráter keynesiano, enquanto que o segundo, ressalta a escala nacional como lócus privilegiado para legitimidade da reprodução do capital, ou seja, "embora economicamente obsoleta, a nação-Estado permanece altamente funcional, politicamente" (Smith, 1988, p. 207). Em outro momento, Smith (2004) relaciona a importância da escala nacional como projetividade dos interesses de uma nação para a escala global; isto é, para o autor, há uma centralidade inegável na escala nacional mesmo diante do período atual conhecido como globalização.

Portanto, a escalaridade é expressão de relações de poder e, no caso da comercialização agrícola, de construção dos parâmetros normativos técnico-logísticos tornados hegemônicos pela maior capacidade de gestão e controle dos agentes com atuação transescalares, isto é, das grandes empresas varejistas.

A difusão de técnicas e normas no atual período econômico - globalização - rebate na construção da espacialidade reticular. As redes geográficas na globalização são ferramentas de análise funda- 
mentais para compreender o jogo assimétrico de poder e, pensando na comercialização agrícola, a construção dinâmica e os meandros da rede de conexão entre a produção familiar na Região Serrana e o consumo na área metropolitana.

\section{Considerações Finais}

A comercialização agrícola é uma etapa inevitável para o produtor rural, repleta de entraves e perspectivas. $\mathrm{O}$ contato (amistoso ou não) do produtor com o mercado representa relações técnicas, políticas, sociais e espaciais. De acordo com Naves (2008),

Nestas relações, as pessoas satisfazem mais do que suas necessidades materiais, uma vez que tais atividades são parte de suas estratégias e projetos de vida. A questão, portanto, não está em escolher relacionar-se ou não relacionar-se com o mercado; está na forma como está relação se dará (p. 151).

Nessa perspectiva, a principal questão estaria na existência e na qualidade (ou não) dos sistemas públicos de regulação de comercialização e nas possibilidades de inserção da produção familiar nas diversas redes configuradas pela articulação dos diversos agentes. A comercialização representa mais uma etapa das relações de poder presentes no espaço social e, por exemplo, no escoamento da produção. Além dos fatores da comercialização em si, outros, como o acesso à terra e as relações sociais de produção, representam indicadores importantes nas redes orientadas para o abastecimento.

Como primeira consideração, entende-se a necessidade de intervenção nos processos de comercialização derivados dos sistemas de parceria típicos da Região Serrana fluminense. $\mathrm{O}$ meeiro paga para trabalhar na terra e ainda tem parte da renda absorvida pelo proprietário durante o processo de comercialização. Nesse sentido, o acesso à terra é um entrave para a aproximação de pro- 
dutores e consumidores e para a redução do preço dos alimentos e o aumento da renda do produtor.

O Estado do Rio de Janeiro apresenta uma área metropolitana marcada pela concentração demográfica e, por isso, é produtora das maiores demandas pelos produtos do circuito Tere-Fri. Apesar da reduzida distância, aproximadamente cem quilômetros, ainda há um abismo de intermediação entre produtores e consumidores, ou seja, os mecanismos logísticos reduziram o tempo de transporte, tornaram os pedidos instantâneos e foram incapazes de ampliar a renda da produção familiar.

Em virtude da demanda gerada pelo consumidor metropolitano, as redes de comercialização tendem a orientar os fluxos para a capital e o seu entorno para tentar manter volumes constantes de produto e evitar problemas de escassez de alimentos. Contudo, a produção agrícola é sazonal, e a capacidade de manutenção do produto não significa a preservação dos preços e da renda do trabalhador agrícola.

As estratégias de reprodução social da produção familiar são múltiplas e envolvem, também, as relações com o peso demográfico da área metropolitana. O circuito Tere-Fri é uma típica área de turismo em espaço rural e também espaço para veranistas. Nesse sentido, o produtor agrícola familiar desempenha algumas funções, isto é, além de ofertar produtos agrícolas, compõe a paisagem e alimenta o mercado de trabalho do turismo.

Da mesma forma, pensando apenas na comercialização, os produtores participam e (re)criam múltiplas estratégias para o escoamento da produção, gerando movimentos de resistência (ou não) e garantindo novas formas para a reprodução social do agricultor familiar. Entretanto, como ressalta Naves (2008),

Pode-se dizer que, mesmo quando os agricultores familiares tentam desenvolver alternativas próprias para enfrentar seus problemas, criando o que se pode chamar de um novo repertório de 
possibilidades e oportunidades em relação àquelas que já existem, ainda assim correm os riscos de terem este mesmo repertório apropriado pelos atores que dominam os espaços ou instâncias nos quais pretendem se inserir (p. 168).

Em sintonia com essa análise, compreende-se o processo de comercialização e a rede de abastecimento como um mecanismo em interação com outras escalas geográficas. Não há, pois, a possibilidade de isolar a distribuição de gêneros agrícolas no território fluminense das transformações em curso na escala nacional e global e, principalmente, em articulação entre elas.

Assim, como afirma Carneiro (2002), há novas racionalidades na construção atual da ruralidade. As verticalidades e as redes sobrepostas recriam simbolismos e normas produtivas pensadas externamente e dialeticamente inseridas no cotidiano de cada local rural. Nesse sentido, o campo admite novas relações com a cidade e novas leituras de suas próprias práticas, ultrapassando, definitivamente, a leitura exclusivista das atividades agrícolas.

No circuito Tere-Fri, as atividades não agrícolas são basicamente definidas pelo turismo e veraneio, com impactos na renda do trabalhador rural. As entrevistas de campo revelaram a complementação da renda agrícola com atividades não agrícolas em várias famílias. Entretanto, Carneiro (2002) relata que as

Mesmas fontes apontam para tendência à pluriatividade em certas regióes do país e, sobretudo, no Estado do Rio de Janeiro. Essa prática pode significar tanto um mecanismo da estratégia de reprodução social de famílias sem condições de se manterem exclusivamente com a atividade agrícola, quanto também pode expressar uma mudança no padrão de exploração agrícola (p. 225).

Entende-se o trabalho não agrícola como um aumento da exploração do trabalhador rural e um processo relacionado ao cir- 
cuito de comercialização. A intermediação apropria-se de parte da renda do trabalho no campo e a renda não agrícola permite a reprodução social das famílias e, por isso, a manutenção da oferta de produtos para a área metropolitana.

O Esquema 4 apresenta a sede global das empresas varejistas transnacionais e suas articulações com atacadistas e operadores logísticos. Um fato interessante é que não há interação direta entre o produtor e o supermercado. De fato, o grupo JFC tem áreas de produção no circuito Tere-Fri, contudo, antes de repassar para o varejista, a empresa agrega valor, separando, classificando, embalando e analisando a qualidade do produto. As redes transnacionais operam tangenciando os atacadistas localizados no CEASA-Rio pela menor capacidade logística do entreposto e, nesse sentido, articulam redes com operadores logísticos mais eficientes, como o grupo JFC e a empresa Tutti-Fruti.

Além dos grandes operadores logísticos, há uma vasta rede montada por empresas de menor porte com interações múltiplas. Essas empresas são articuladas com empresas de logística maiores e, principalmente, com o a capital do Estado via CEASA-Rio ou diretamente para varejistas de menor porte. Um elemento interessante dessa rede é o operador especializado. Na verdade, são empresas dedicadas aos produtos mais raros no circuito Tere-Fri, como uma forma de terceirização de uma função específica dos maiores operadores logísticos.

As redes varejistas nacionais seguem um modelo transnacional de organização da rede de distribuição. Entretanto, há uma combinação de possibilidades, isto é, além de terceirizar o processo de transporte para as filiais, os supermercados podem manter vínculos com os atacadistas do CEASA-Rio e contratar empresas para a entrega nas filiais - caso da rede de supermercados Mundial.

Os produtores são inseridos (se inserem) e marginalizados (se excluem) das conexões de acordo com suas possibilidades e necessidades de reprodução social. Há, por isso, produtores conectados ao 
CEASA-RJ e, essencialmente, proprietários (não necessariamente produtores) realizando a função das empresas de operação logística.

A capacidade de gestão dos fluxos é maior dos supermercados pela maior capacidade técnica e maior poder na geração de demanda por produtos. Isso posto, esta análise revela a perspectiva transescalar das redes varejistas e a assimetria na sua atuação em comparação com os produtores e operadores logísticos. Seguindo nessa linha, o Esquema 4 também posiciona a empresa de logística ao lado do sistema CEASA-Rio. Entende-se que o entreposto comercial definitivamente não concorre com os supermercados e sua função de entreposto comercial público torna-se privada pela atuação desses operadores.

As políticas públicas de modernização técnica e coordenação organizacional dos Ceasas tendem a fomentar a concorrência do entreposto público com os operadores logísticos, ratificando, consequentemente, o papel central das grandes redes varejistas transnacionais ou nacionais. Portanto, ratifica-se a centralidade dos supermercados pela capacidade de orientar e gerenciar os fluxos de comercialização agrícola ao longo da cadeia de suprimentos, assim como se repete a apropriação privada do entreposto público.

As práticas neoliberais e contextualizadas pela acumulação flexível impulsionam a capacidade competitiva e gerencial das grandes firmas transnacionais, por exemplo, das fusões e aquisições de empresas nacionais. A otimização de práticas logísticas e a flexibilização das relações trabalhistas também evidenciam fatores de crescimento da capacidade de gestão das grandes varejistas. Para Flexor (2008),

O ambiente econômico da década de 1980, marcado pela reestruturação industrial e a ideologia neoliberal do governo Reagan, facilitou a difusão das práticas trabalhistas e a cultura empresarial favorável às empresas. No Wal-Mart, a atuação dos sindicatos foi limitada ao máximo e os salários, outro importante componente dos custos no setor do varejo, forma comprimidos (p. 67). 
A configuração organizacional do Wal-Mart e das outras grandes redes transnacionais (re)estabeleceu normas e parâmetros para a logística, relações entre empresas e funções desempenhadas na distribuição de gêneros agrícolas. O cenário nacional e fluminense do abastecimento agrícola não conheceu as empresas transnacionais do varejo na abertura neoliberal efetivada e potencializada na década de 1980. As transformações não decorrem da presença do capital internacional em si; na verdade, o cenário proposto pela globalização indica novas escalas de competição e, mesmo reforçando características competitivas nacionais, imprime características normativas exógenas aos circuitos aparentemente de base local.

\section{Referências}

ANDERSON, P. "Balanço do neoliberismo". In SADER, E. e GENTILI, P. (Orgs.) Pós-neoliberalismo: as políticas sociais e o Estado democrático. Rio de Janeiro: Paz e Terra, 1995. pp. 9-23.

ANTUNES, R. Os sentidos do trabalho. São Paulo: Boitempo, 2001.

BECKER, B. K. "O mercado carioca e seu sistema de abastecimento". Revista Brasileira de Geografia, 28(2). Rio de Janeiro: IBGE, 1966.

BERG, N. e ROBERTS, R. Walmart: A estratégia vencedora do gigante do varejo mundial. Rio de Janeiro: Elsevier, 2012.

BERMAN, M. Tudo que é sólido desmancha no ar. São Paulo: Companhia das Letras, 1999.

. Aventuras no marxismo. São Paulo: Companhia das Letras, 2001.

BRANDÃO, C. A. "O Modo Trans-escalar de Análise e de Intervenção Pública: notas para um manifesto anti-localista”. In ENCONTRO NACIONAL DA ANPUR, X. Belo Horizonte, 2003. pp.1-12.

BOXBERGER, G. e KLIMENTA, H. As Dez Mentiras da Globalização. Alternativas para Combater o Mercado todo Poderoso. São Paulo: Aquariana, 1999.

CARLOS, A. F. A. A condição espacial. 1. ed., v. 1. São Paulo: Contexto, 2011. 
CARNEIRO, M. J. "Multifuncionalidade da agricultura e ruralidade: uma abordagem comparativa". In MOREIRA, R. e COSTA, L. F. (orgs). Mundo rural e cultura. Rio de Janeiro: Mauad, 2002. pp. 223-40.

CASTRO, I. E. "O problema da escala”. In: CASTRO, I.E. et al. Geografia Conceitos e Temas. $3^{\text {a }}$ ed. Rio de Janeiro: Betrand Brasil, 2001. p.117-140.

CHESNAIS, F e SAUVIAT, C. "O financiamento da inovação no regime global de acumulação dominado pelo capital financeiro". In: LASTRES, H. et al. Conhecimento, sistemas de inovação e desenvolvimento. Rio de Janeiro: Contraponto, 2005.

DELGADO, N. G. "Negociações comerciais internacionais e agricultura familiar no primeiro Governo Lula. Avanços e impasses”. In LIMA, E. N. DE et al (Orgs.). Mundo Rural IV. Configurações Rural-Urbanas: Poderes e Políticas. v. 1, 1ed. Rio de Janeiro: Mauad X-Edur/UFRRJ, 2008. pp. 171-97.

FERNÁNDEZ, V. R. Desarrollo regional bajo transformaciones transescalares ¿Por qué y cómo recuperar la escala nacional? Mimeo, 2009.

FERREIRA, C. O Fordismo, sua crise e algumas considerações sobre o caso brasileiro. v. 7, n. 2. Belo Horizonte: Nova Economia, 1997. pp. 165-201.

FLEXOR, G. A globalização do varejo e seus impactos no Brasil: o caso do WAL-MART. Mundo Rural Brasileiro: ensaios interdisciplinares. Rio de Janeiro: MAUAD, 2008.

HARVEY, D. Condição Pós-Moderna: uma pesquisa sobre as origens da mudança cultural. 12 ed. São Paulo: Loyola, 2003.

. O Novo Imperialismo. São Paulo: Edições Loyola, 2004. . A produção capitalista do espaço. São. Paulo: Annablume, 2005.

. O Enigma do Capital e as crises do Capitalismo. São Paulo: Boitempo, 2011.

. O Neoliberalismo: história e implicações. 3. ed. São Paulo: Edições Loyola, 2012.

. Para entender o capital. Livro I. São Paulo: Boitempo Editorial, 2013.

. Banco de Dados Agregados. Sistema IBGE de Recuperação Automática - SIDRA. Disponível em: http://www.ibge.gov.br. Acesso em: nov. 2019. 
LASTRES, H e FERRAZ, J. "Economia da Informação, do Conhecimento e do Aprendizado". In LASTRES, H e ALBAGLI, S. (orgs.). Informação e globalização na era do conhecimento. Rio de Janeiro: Campus, 1999.

LIPIETZ, A. Audácia: uma alternativa para o século 21. São Paulo: Nobel, 1991.

MOREIRA, R. J. “Configurações de poderes urbano-rurais: fragmentos de discursos e práticas”. In: MARAFON, G. et al. (orgs). Abordagens teórico-metodológicas em geográfica agrária. Rio de Janeiro: UERJ, 2007.

MOREIRA, R. "Uma Análise Crítica do Modelo de Desenvolvimento do Estado do Rio de Janeiro". In: O Estado do Rio no Início do Século XXI: Olhando para ofuturo. Rio de Janeiro: Universidade Federal Fluminense, 2001. pp. 127-32.

NAVES, F. "Construção, subversão e submissão: reflexões sobre estratégias de acesso ao mercado adotadas por agricultores familiares agroecológicos". In SECRETO, M. et al. O Campo em Debate: terras, homens, lutas. Seropédica: EDUR, 2008.

PALMEIRA, J. N. e TENÓRIO, F. G. Flexibilização organizacional: aplicação de um modelo de produtividade total. Rio de Janeiro: FGV Eletronorte, 2002.

RUA, J. "As crises vividas pelo estado do Rio de Janeiro e a emergência de novas territorialidades em áreas rurais". In MARAFON, G. et al. Abordagens teórico-metodológicas em Geografia Agrária. Rio de Janeiro: EDUERJ, 2007. pp. 271-98.

SANTOS, M. Por uma outra globalização - Do pensamento único à consciência universal. Rio de Janeiro: Record, 2000.

. A natureza do Espaço: técnica e tempo, razão e emoção. São Paulo: Edusp. 2002.

. Por uma geografia nova. São Paulo: Edusp, $2002 b$.

. Da totalidade ao lugar. São Paulo: Edusp, 2005.

SILVEIRA, R. “Complexo agroindustrial, rede e território”. In: DIAS, L e SILVEIRA, R. Redes, Sociedade e Território. Santa Cruz do Sul: EDUNISC, 2005.

SMITH, N. Desenvolvimento Desigual. Rio de Janeiro: Bertrand Brasil, 1988. 
- Geografias perdidas y globalizaciones fracasadas. De Versalles a Irak. Documents d'Anàlisi Geográfica. Barcelona: Universitat Auto noma de Barcelona, n. 4, 2004. pp. 19-41.

SOARES, W. "Desenvolvimento e capital social: da análise de redes sociais ao recorte teórico das desigualdades”. In: MATOS, R. e SOARES, W. (Orgs.). Desigualdades, redes e espacialidades emergentes no Brasil. Rio de Janeiro: Garamond, 2010. p. 59-90.

SOBARZO, O. "O urbano e o rural em Henri Lefebvre". In: SPOSITO, M. E. B. e WHITACKER, A. M. Cidade e campo: relações e contradições entre urbano e rural. São Paulo: Expressão Popular, 2006. pp. 53-64.

SOJA, E. Geografia Pós-Moderna. 2 ed. Rio de Janeiro: Jorge Zahar, 1993.

VIEIRA, D. J. "Estado Nacional e Escalas Geográficas: uma abordagem exploratória a partir de Neil Smith”. Revista Paranaense de Desenvolvimento, Curitiba, n. 123, pp. 161-78, jul.-dez. 2012.

WOODS, M. Rural. New York: Routledge, 2011. 